\title{
Modeling of Tractor Fuel Consumption
}

\author{
Bronisław Andrzej Kolator (D)
}

check for

updates

Citation: Kolator, B.A. Modeling of Tractor Fuel Consumption. Energies 2021, 14, 2300. https://doi.org/ $10.3390 /$ en 14082300

Academic Editor: Constantine D. Rakopoulos

Received: 19 March 2021

Accepted: 14 April 2021

Published: 19 April 2021

Publisher's Note: MDPI stays neutral with regard to jurisdictional claims in published maps and institutional affiliations.

Copyright: (C) 2021 by the author. Licensee MDPI, Basel, Switzerland. This article is an open access article distributed under the terms and conditions of the Creative Commons Attribution (CC BY) license (https:// creativecommons.org/licenses/by/ $4.0 /)$.
Faculty of Technical Sciences, University of Warmia and Mazury in Olsztyn, Oczapowskiego 11 Street, 10-719 Olsztyn, Poland; kolator@uwm.edu.pl

\begin{abstract}
In this paper, the energy diagnostic of tractor performance consists in evaluating the energy (fuel consumption per hectare- $\mathrm{dm}^{3} \mathrm{ha}^{-1}$ ) for a given agricultural operation and in combining it with working capacity, also called productivity (area productivity-ha $\mathrm{h}^{-1}$ ). One of the methods of solving this problem is the identification of the functioning process of the machine unit. A model of the process of the machine unit performance was developed, considering the operation of the rear linkage system of the implement with the force control adjustment system. In order to analyze the system, a mathematical model of the system function was built: tractor-implement-soil, defining the physical connections and interdependencies between the individual subsystems of the system. Based on this model, a simulation model was developed and implemented in the Matlab/Simulink environment. The Simulink package was used to test the performance of the machine set. The efficiency indicators according to the adopted criteria were calculated in the evaluation block. To evaluate the process, the technical and operational parameters of the tractor, the type and parameters of the tool, and soil properties were taken into account. The results of simulation studies obtained on a validated model are consistent with experimental data from appropriate soil conditions.
\end{abstract}

Keywords: tractor; fuel efficiency; total efficiency; simulation model; three-point hitch; draft control

\section{Introduction}

Tractor energy inputs are often assessed through tractor-oriented test procedures that reflect a variety of agricultural operations. Suspended tools and machines are typically connected to the tractor through a three-point rear linkage system. Their position with reference to the tractor can be changed using the controlling devices of this system. Aiming at the efficiency of the tractor unit performance and improvement of the tractor's operation comfort, constant improvements in the systems for automatic control of the implement/machine linkage system are required.

The problem of drawbar pull efficiency has been discussed in numerous theoretical and empirical studies, many of which analyzed wheel-soil interactions in view of the tractive efficiency ratio. A graphic method of forecasting tractor performance in the field for two-wheel drive tractors on soils with descriptive hard, arable, and soft or sandy strengths is presented in [1]. A model for predicting the traction wheel was developed in [2]. Various parameters influencing the required torque, axle load, and turning radius were included in the analysis. Experiments were carried out to investigate the effects of various wheel and system parameters on torque and energy consumed per unit distance traveled. In [3], a comprehensive method for predicting the off-road performance of a driven wheel is presented, in longitudinal direction. A model was developed for prediction of the traction performance, with a view toward optimizing the operating performance of the vehicles. Operation at the maximum drawbar pull should be limited due to a very low tractive efficiency-high drive wheel slip values [4-6]. In [7], a semiempirical model of soil-tire interaction is presented, adapted to simulate the traction properties of tractors. Towing performance and specific fuel consumption were presented in [8] for the Mechanical Front-Wheel Drive (MFWD) tractor on various areas of the field. Curves show 
the dependence of tractive force, tractive efficiency, and specific fuel consumption on the dynamic traction and slip coefficient.

The problem of tractor performance with an implement suspended on a three-point linkage system has been examined by numerous researchers [9-12], which are theoretical studies confirmed by the results of experimental research.

Using a fixed linkage system, the implement is rigidly coupled on one side with the tractor in the vertical plane and, because of that, it is guided at a specific operating height or depth. In the working position of suspended implements or machines, the tractor is subject not only to a horizontal drawbar pull, but also to vertical forces, i.e., weight and components of working loads of an implement or a machine [13]. Fixed systems require the application of automatic control of the tool position. Systems for controlling the linkage system of the implements currently used in agricultural tractors are based on mechanical or, increasingly often, electronic systems $[14,15]$. The applied systems of the operating position of the implement suspended on a three-point rear linkage system provide the following control possibilities: position, force, mixed, and slide, as well as pressure adjustment in some tractors. The analysis of the performance of the tractor aggregate using force and slide controlling is presented in research papers [16,17]. Improving traction performance and power transfer indices of wheeled tractors and field terrain soil with higher traction at optimal travel reduction can optimize energy utilization [18].

Computer simulation is one of the advanced and modern methods widely used for solving problems in the processes of tractor and agricultural machine performance [19-21]. The fuel efficiency of the tractor during rotary tillage was predicted using numerical modeling. A numerical model was developed using Simulation X [22].

Models of tractors with a power-shift transmission and precise pneumatic planter with an electric-driven seed metering device are developed and built as research objects and simulated using Matlab with Simulink [23]. Energy management strategy based on the optimal system efficiency and a dual-motor-driven electric tractor model was built in Matlab/Simulink (2018a) [24].

The development of proper decision-support systems for implementing precision decisions remains a major stumbling block to adoption [25]. With the development of precision agriculture, the tractor is developing as a major and crucial power machinery component.

This study presents simulation results and their analysis during the operation of the tractor aggregate by using an automatic system of force control to adjust the implement linkage system.

\section{Materials and Methods}

\subsection{Machine Unit}

The object of the research was the performance of a machine unit during soil cultivation. The experimental research was conducted with a unit composed of a rear-wheel drive agricultural tractor Ursus MF 235 and a suspended cultivator. A view of the machine unit during field tests is shown in Figure 1.

The Ursus MF 235 tractor (1986 year of production) was equipped with an AD 3.152 Perkins direct injection engine (three-cylinder diesel), with $2.502 \mathrm{dm}^{3}(152.0 \mathrm{cu}-$ bic in) cylinder capacity. Rated engine power is $28 \mathrm{~kW}$ at $209 \mathrm{rad} \mathrm{s}^{-1}$ and the maximum torque is $147 \mathrm{Nm}$ at $146 \mathrm{rad} \mathrm{s}^{-1}$. The torque is transmitted from the engine through double-plate dry clutch. The first plate transmits torque through the five-speed gearbox, two-stage planetary reduction gear and the final drive with a differential mechanism to drive the wheels. The second plate transmits torque to the hydraulic pump. The tractor was equipped with 12.4 R28 radial wheels mounted at the rear and 6.00 R16 at the front.

The attached cultivator was equipped with heavy spring-loaded tooth with duckfoot shares, the operating width of the cultivator $b_{n}$ was $2.13 \mathrm{~m}$ and the maximum soil cutting depth $a_{n}$ was $0.2 \mathrm{~m}$. 


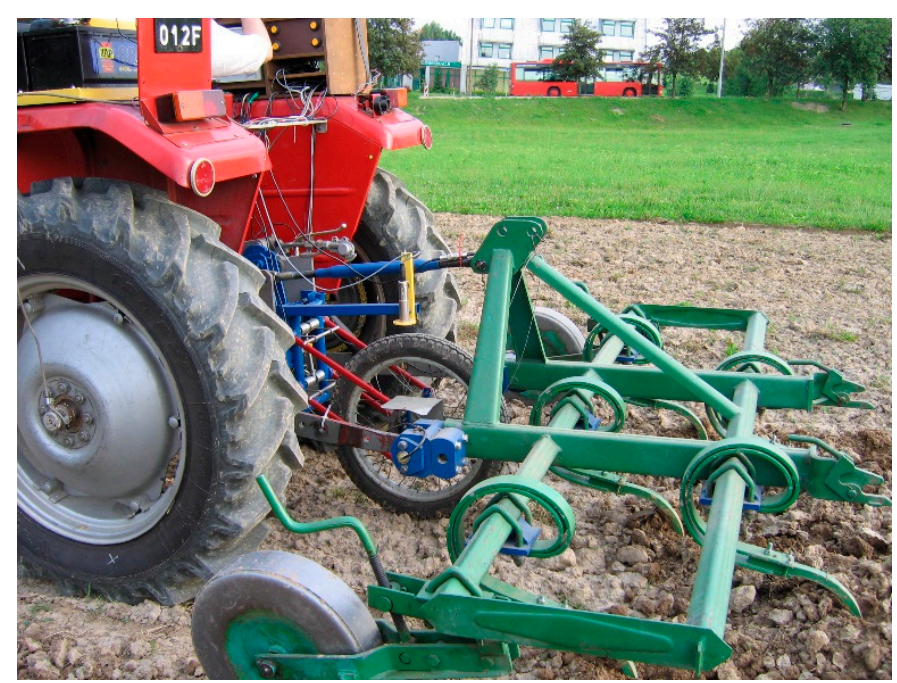

Figure 1. A view of the machine unit during field tests.

The total weight of the tractor unit was $2375 \mathrm{~kg}$. The load on the rear wheels was $1530 \mathrm{~kg}$, and the remaining part of the machine unit weight was on the front axle.

A schematic of the sensors mounted on the machine unit (converters), which reproduce measurement signals (Figure 2) made it possible to record over time the following values:

1. Instantaneous fuel consumption $G_{t}$-with a fuel gauge Flowtronic 215.

2. Actual linear velocity of the tractor $v$ - with a radar II DICKEY-JOHN type DJRVSII.

3. Oil pressure $p_{h}$ in the hydraulic system of the implement linkage system-P8AP pressure sensor $(20 \mathrm{MPa})$ by HBM.

4. Implement position with reference to the tractor $h_{p}$-mutual inductance sensor (LVDT) Bosch EHR system sensor.

5. Force in the upper linkage bar $F_{l g}$ - custom made, calibrated tensometer.

6. Force in linkage lower bars, left $F_{l l}$ and right $F_{l p}$-elastomagnetic sensors, Bosch EHR system sensor.

7. Force in hangers, left $F_{w l}$ and right $F_{w p}$-custom made, calibrated tensometers;

8. Angular velocity of the tractor's rear wheels $\omega_{k r}$-induction sensors PCID- $4 \mathrm{ZN}$ (2 pcs).

9. Torques of rear wheels, left $T_{w l}$ and right $T_{w p}$-custom made, calibrated tensometers.

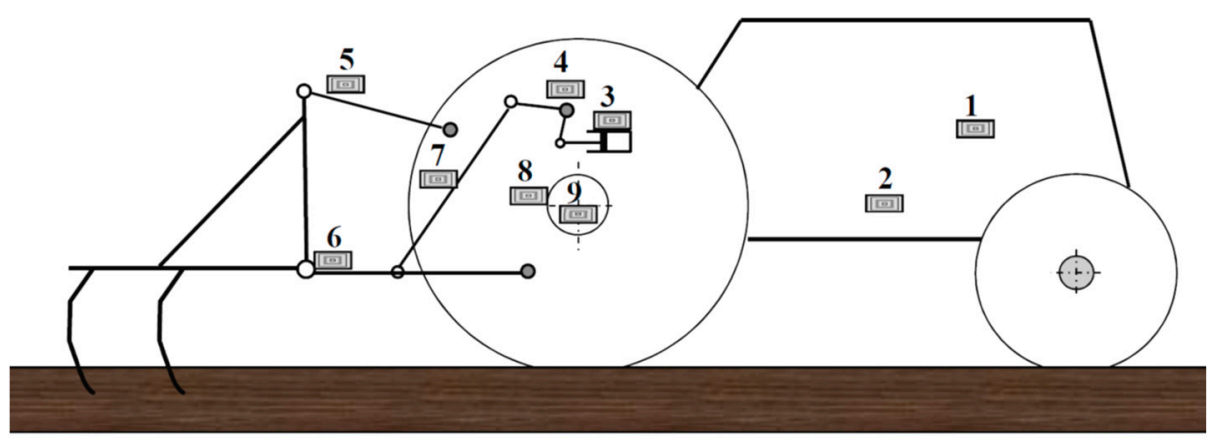

Figure 2. The scheme for placement of measurement sensors on the machine unit: 1-Flowtronic 215 fuel gauge; 2-II DICKEY-JOHN radar; 3-P8AP pressure converter; 4-LVDT implement linkage position sensor; 5 -tensometer for measuring force in the upper linkage bar; 6-elastomagnetic sensors for measuring longitudinal forces in lower linkage bars (left and right); 7-tensometers for measuring forces in hangers (left and right); 8-PCID-4 ZN induction sensors of drive wheel angular velocity (2 pcs); 9-tensometers to measure torques of drive wheels (left and right).

A set of Spider 8 analog-digital converters (manufactured by HMB) was used for processing signals from the sensors in the measurement system. The set featured 24 channels 
and software for operating the converters, Catman 32. A TOUGHBOOK Panasonic CF-28 computer was used to collect the values registered in the field tests.

The aim of the field test was to determine energy demand during the soil cultivation and, in particular, the resistance force depending on the applied system of automatic control of the implement linkage system and the cultivated soil profile. Sample curves for recorded changes in the torques of wheel $T_{w}$, drawbar pull $F_{d}$, and driving force $F_{n}$, and for hydraulic pressure $p_{h}$ position of the implement linkage $h_{p}$ in the system for the automatic control of the implement linkage with the force option enabled, for the soil profile and the gear, respectively, are presented in Figures 3 and 4.

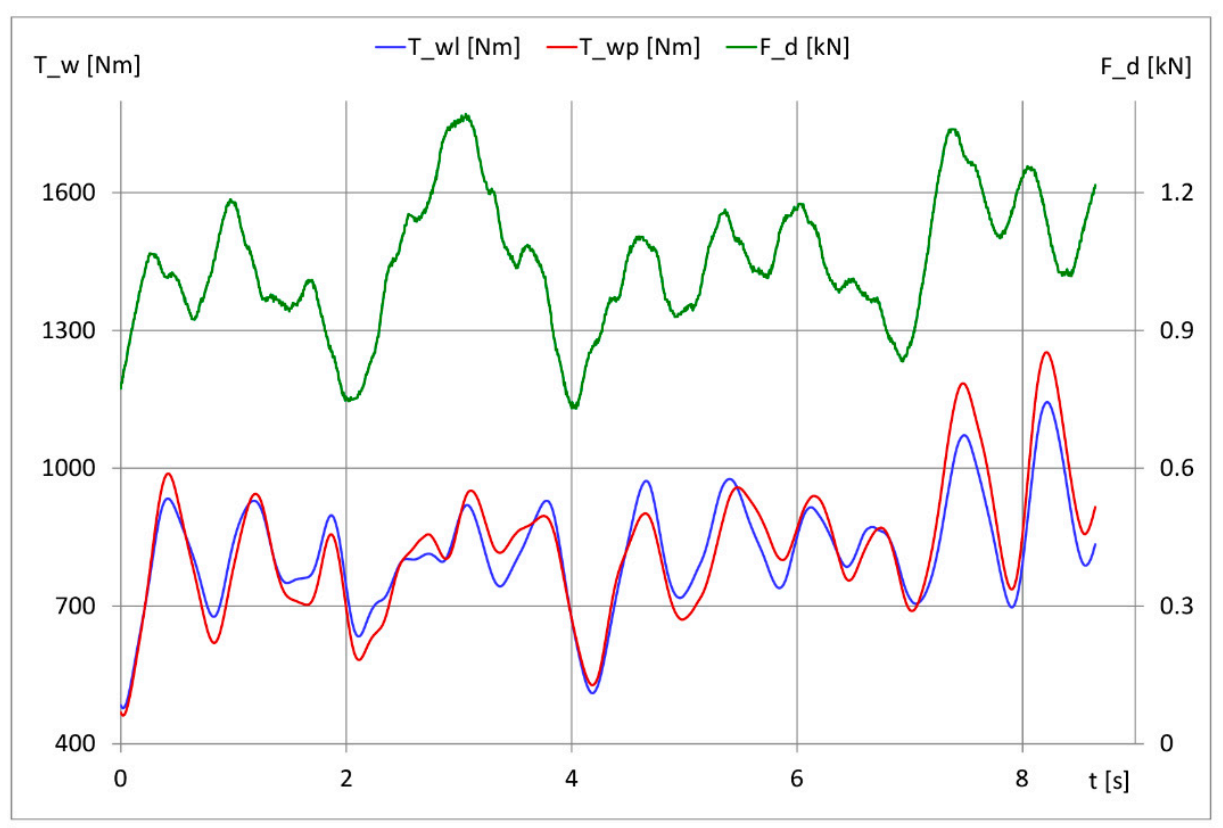

Figure 3. Changes in time of torques on wheels $T_{w}$ and drawbar pull $F_{d}$; soil profile-loamy sand, second gear, operating depth $0.09 \mathrm{~m}$.

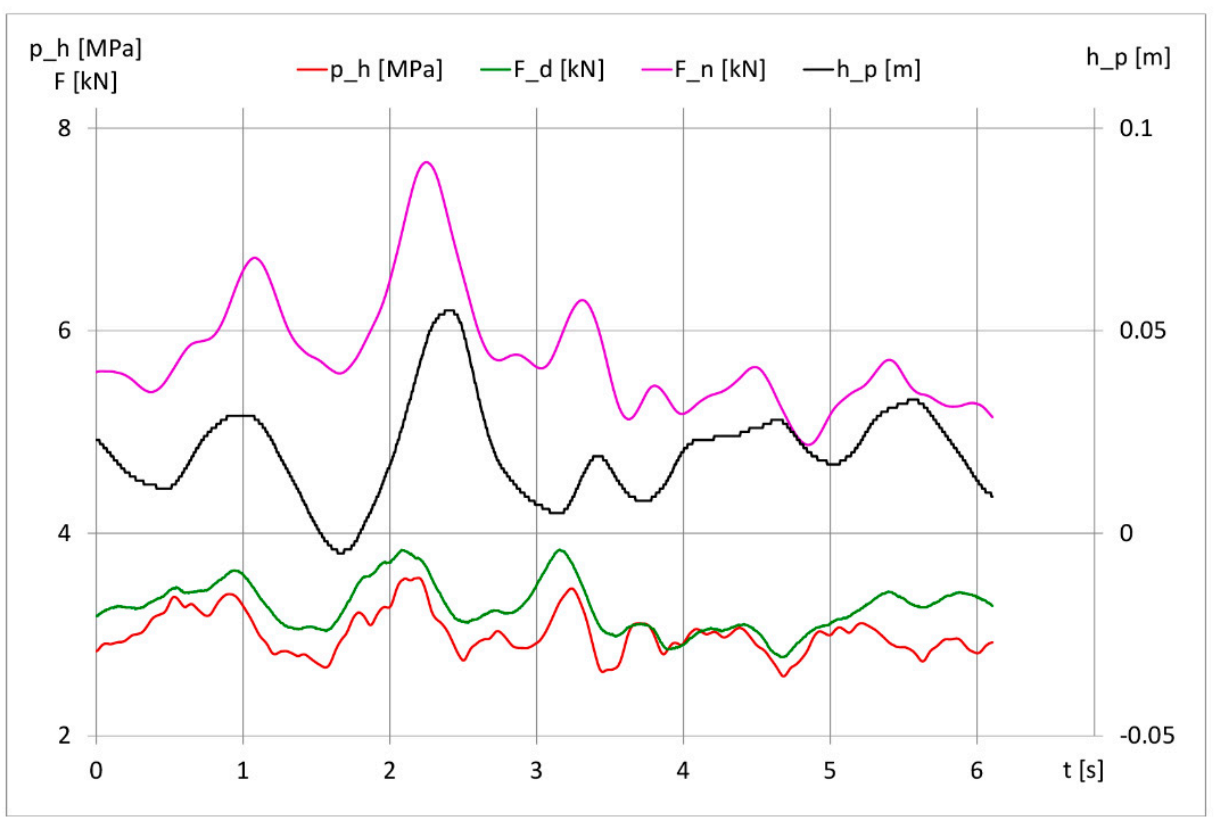

Figure 4. Changes in time of hydraulic pressure $p_{h}$, drawbar pull $F_{d}$, driving force $F_{n}$, and position of the implement linkage system $h_{p}$; soil profile—-medium clay, third gear, operating depth $0.09 \mathrm{~m}$. 
As a result of carrying out experimental research concerning the performance of the machine unit according to the methodology developed, a set of data was obtained that was required to build a computer model to be used for simulated tests of the tractor-implementsoil system.

\subsection{Tractor Performance Indicators}

Traction coefficient (tractive efficiency) $\eta_{u}$ was defined as a relation of the drawbar pull $P_{u}$ to the power delivered to the drive wheels of the tractor $P_{w}$ and described by the following relation:

$$
\eta_{u}=\frac{P_{u}}{P_{w}}=\frac{F_{d} \cdot v}{T_{w} \cdot \omega_{w}}
$$

where $P_{u}$-pulling power $(\mathrm{kW}), P_{w}$-power delivered to drive wheels $(\mathrm{kW}), F_{d}$-drawbar pull of the tractor $(\mathrm{N}), v$-actual tractor velocity $\left(\mathrm{m} \mathrm{s}^{-1}\right), T_{w}$-torque of the drive wheel $(\mathrm{N} \mathrm{m})$, and $\omega_{w}$-angular velocity of the drive wheel $\left(\mathrm{rad} \mathrm{s}^{-1}\right)$.

Wheel slip s was described using the following formula:

$$
s=1-\frac{v}{v_{t}}=\frac{v}{r_{d r} \cdot \omega_{w}}
$$

where $s$-drive wheel slip, $v_{t}$ - theoretical tractor velocity $\left(\mathrm{m} \mathrm{s}^{-1}\right)$, and $r_{d r}$-dynamic radius of rear wheel (m).

Theoretical velocity $v_{t}$, is the product of a dynamic radius $r_{d r}$ of the drive wheel and its angular velocity $\omega_{w}$. This velocity is determined as a quotient of the crankshaft angular velocity $\omega_{e}$ and transmission of the total drive train $i_{c}$ :

$$
v_{t}=\omega_{e} \frac{r_{d r}}{i_{c}}
$$

After taking into account Formula (2) describing the slip in Equation (1), a formula for tractive efficiency $\eta_{u}$ of tractor wheels was obtained:

$$
\eta_{u}=\frac{F_{d} \cdot r_{d r}(1-s)}{T_{w}}
$$

Total efficiency $\eta_{o}$ of the machine unit was described using the relation:

$$
\eta_{o}=\frac{P_{u}}{g_{e} \cdot P_{e} \cdot W_{d}}=\frac{F_{d} \cdot v}{g_{e} \cdot \omega_{e} \cdot T_{e} \cdot W_{d}}
$$

where $g_{e}$-specific fuel consumption $\left(\mathrm{g} \mathrm{kW} \mathrm{h}^{-1}\right), P_{e}$ - power of engine $(\mathrm{kW}), W_{d}$-calorific value of fuel $\left(\mathrm{kJ} \mathrm{kg}^{-1}\right), \omega_{e}$-angular velocity of the engine shaft $\left(\mathrm{rad} \mathrm{s}^{-1}\right)$, and $T_{e}$ - torque of the engine $(\mathrm{N} \mathrm{m})$.

Area productivity $W_{b}$ per unit of time was determined with the relation:

$$
W_{b}=b_{n} \cdot v
$$

where $b_{n}$-soil cutting width (m).

The relation of the fuel consumption per hour $G_{e}$ to the surface efficiency $W_{b}$ is fuel consumption $G_{p}$ per unit of the cultivated field area:

$$
G_{p}=\frac{G_{e}}{W_{b}}=\frac{g_{e} \cdot P_{e}}{b_{n} \cdot v}
$$

These indicators of the machine unit were used for evaluating its performance during the process of loosening the soil to the required cutting depth. 


\subsection{Simulation Model}

Simulation tests of the machine unit performance require appropriate computer software. The dependencies obtained in laboratory and field tests were used for constructing and validating the simulation model. In the Matlab environment, a simulation model was developed based on the results of experimental studies and a mathematical model of the three-point implement linkage system. This model describes relations occurring in the three-point implement linkage system, and their effect on the performance of the entire machine unit. The program developed in the Simulink suite (Matlab) makes it possible to perform simulation tests with variants of the machine unit operation, whose schematic is shown in Figure 5. The general layout of the simulation program from the Simulink suite used for testing the machine unit performance is constructed of the following blocks:

1. Settings - to introduce the setting for the soil cutting depth, a gear choice, accelerator level position (to maximum setting);

2. Controlling system-to select one of the three implement linkage systems, i.e., $K$-support, $C$-pressure, or $S$-force;

3. Soil profile characteristics-values describing physical and mechanical properties of individual soil types;

4. Cultivator - to determine resistance forces for soil cutting as a function of the threepoint linkage position;

5. Evaluation criteria-to determine performance indicators according to the assumed criteria;

6. Tractor-contains five subsystems. The diagram of the tractor's power unit is shown in Figure 6.

- Perkins AD 3.152 engine of the MF 235 tractor,

- Drive train,

- Tractor hull-rear drive wheels,

- Hydraulic and automatic system,

- Implement linkage system (TUZ).

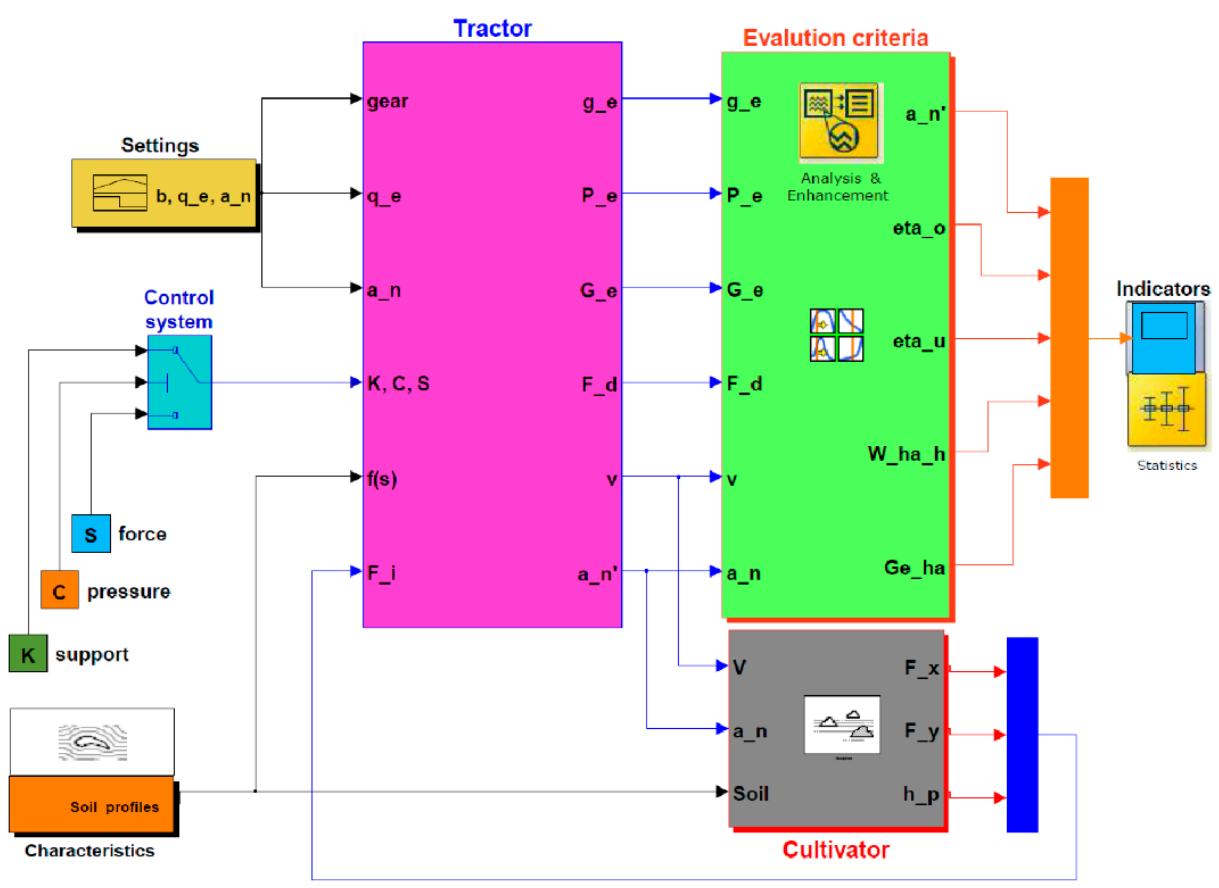

Figure 5. General layout of the Simulink suite program for simulation studies of the machine unit. 


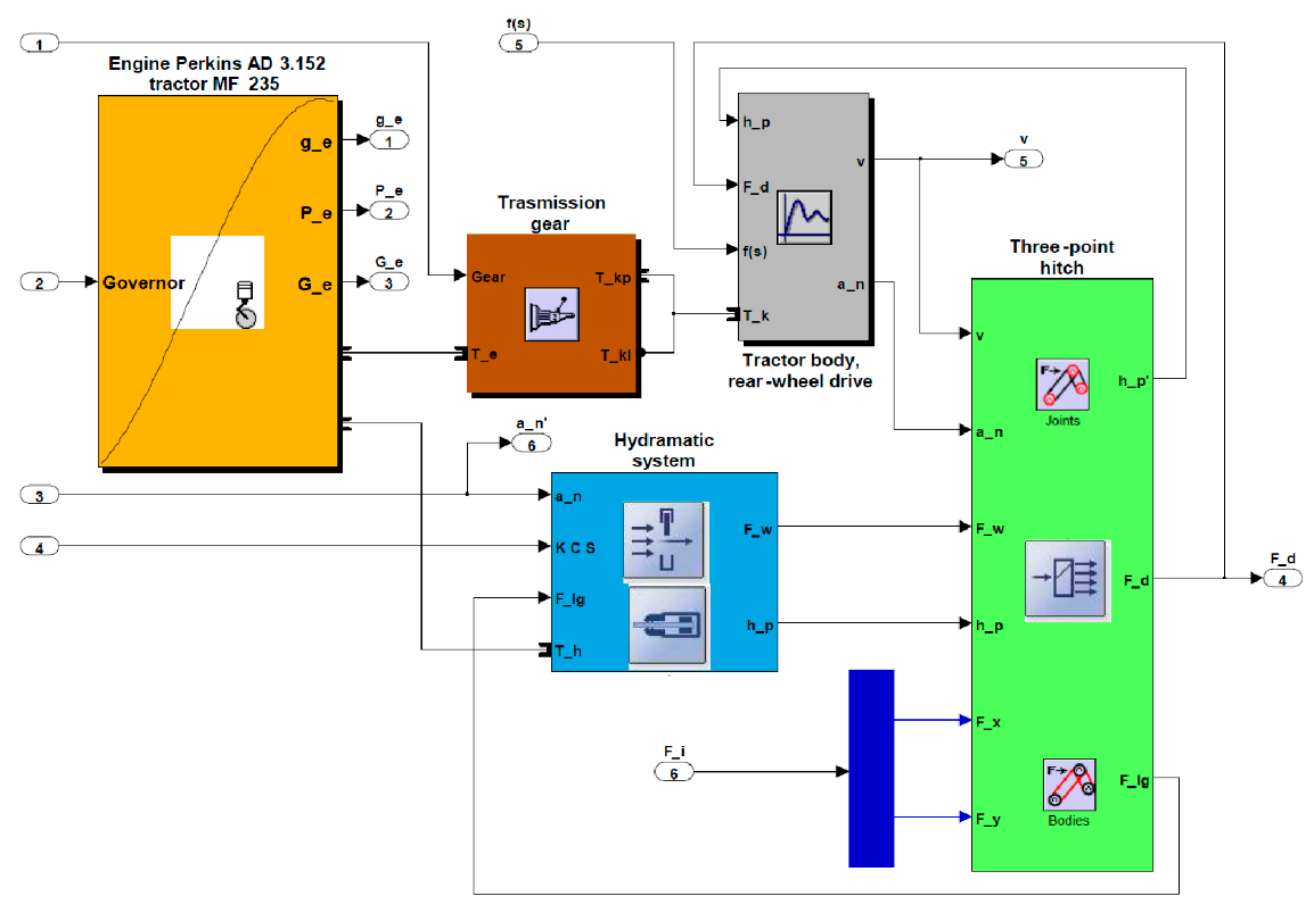

Figure 6. Scheme of the tractor subsystem in the Simulink suite program for simulation studies of the machine unit.

The operation of the tractor engine, in terms of its loads and speed, generates torque and fuel flow data, from which this performance map is drawn [26]. On the basis of experimental studies, the characteristics of the tractor's diesel engine operation in the entire range of its full load and speed as well as specific fuel consumption were developed. In the engine subsystem (Engine Perkins AD 3.152, tractor MF 235) of the Simulink suite program, based on the controlling characteristics of the engine, taking into account fuel dosage settings $q_{e}$ and crankshaft angular velocity $n_{e}$, the engine torque $T_{e}$, transmitted to the drive train subsystem was determined:

$$
T_{e}=f\left(n_{e}, q_{e}\right)
$$

In the drive train subsystem, the torque of wheels $T_{k}$ is determined. With this aim in view, a signal describing engine torque $T_{e}$ is introduced to the subsystem. Additionally, the subsystem includes information about the total transmission of the drive train system $i_{c}$ and its mechanical efficiency $\eta_{m}$ :

$$
T_{k}=f\left(T_{e}, i_{c}, \eta_{m}\right)
$$

In the tractor hull-rear drive wheels subsystem, the value of driving force $F_{n}$ based on torque $T_{k}$ transmitted to the rear wheels of the tractor of an appropriate dynamic radius $r_{d}$ is determined, after taking into account the response of the tractor's rear wheels $R_{r}$ and slip of the tractor's drive wheels $s$. The slip value of the tractor's drive wheels was determined taking into account the coefficient of tractor's wheel traction $\mu$ :

$$
F_{n}=f\left(T_{k}, r_{d}, R_{r}, s(\mu)\right)
$$

The value of the drawbar pull of the tractor $F_{d}$ is determined in the implement linkage system (TUZ) subsystem. Its value depends on empirical coefficients of implement resistance coefficients $B_{1}, B_{2}$, operating width $b_{n}$, and depth $a_{n}$ of the implement, and the linear velocity of the unit $v$ :

$$
F_{d}=f\left(B_{1}, B_{2}, b_{n}, a_{n}, v\right)
$$


Relations (8-11) are presented in more detail in [27].

\section{Results}

\subsection{Validation of Simulation Model}

A test stand was built, consisting of a tractor with a tool. Laboratory analysis and field tests were carried out in order to obtain input data for the verification and validation of the developed model and simulation of tractor operation according to the Matlab/Simulink computer application.

The proposed model of the machine unit performance was validated on the basis of experimental data obtained in field tests. A modified Nash-Sutcliffe coefficient was used as a measure of the model efficiency for experimental values [28,29]:

$$
N S=1-\frac{\sum_{i=1}^{N}\left|S_{i}-O_{i}\right|}{\sum_{i=1}^{N}\left|O_{i}-O_{\text {mean }}\right|}
$$

where $S$-model simulated output; $O$-observed variable; $O_{\text {mean }}$-mean of the observations that the NS uses as a benchmark against which performance of the model is compared; and $N$-total number of observations. NS values range from negative infinity to 1 , where 1 shows a perfect model. NS is zero, implying that the observed mean is as good a predictor as the model, and if NS is less than zero, then the model is a worse predictor than $Q_{\text {mean }}$. Therefore, the higher the value reached by the NS coefficient, the better the model is describing experimental data.

Figure 7 presents the curve for the measured drawbar pull of the tractor $F_{d}$ with an enabled force control system from the start of the unit traveling to the end of the measurement. The warming of the unit was recorded for the time interval of $0-5 \mathrm{~s}$ and proper operation of the unit in seconds 5 to 32 . This force is the input value for the simulation program during its validation.

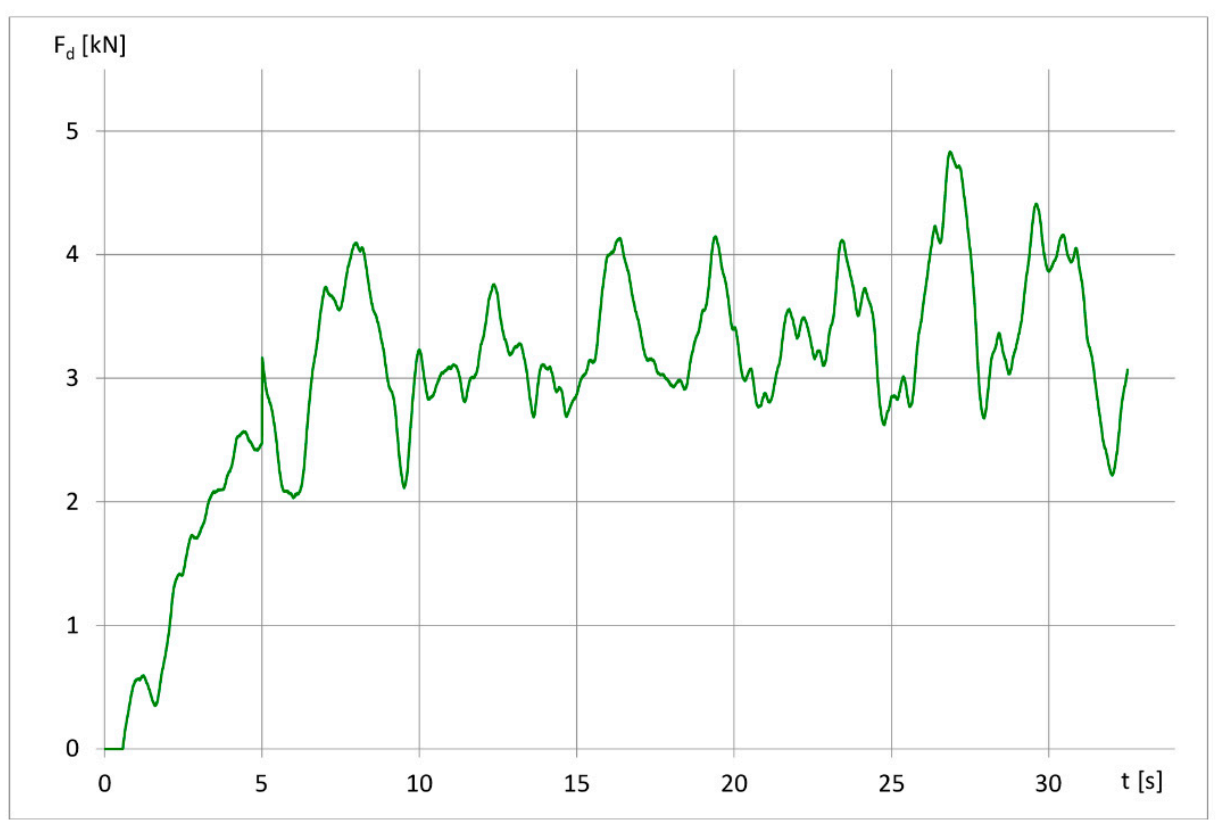

Figure 7. Changes in time of the measured drawbar pull of the tractor $F_{d}$ with enabled force control system; soil profile—silty loam, first gear.

The values selected for the validation of the model included the angular velocity of the drive wheel $\omega_{w}$, linear velocity of the unit $V_{p}$ as presented in Figure 8, torque of the drive wheel axle shaft $T_{w}$, and driving force of the tractor $F_{n}$ as presented in Figure 9. 
Measurement values are marked with the letter $\boldsymbol{M}$, while those obtained from simulation tests are marked with the letter $S$.

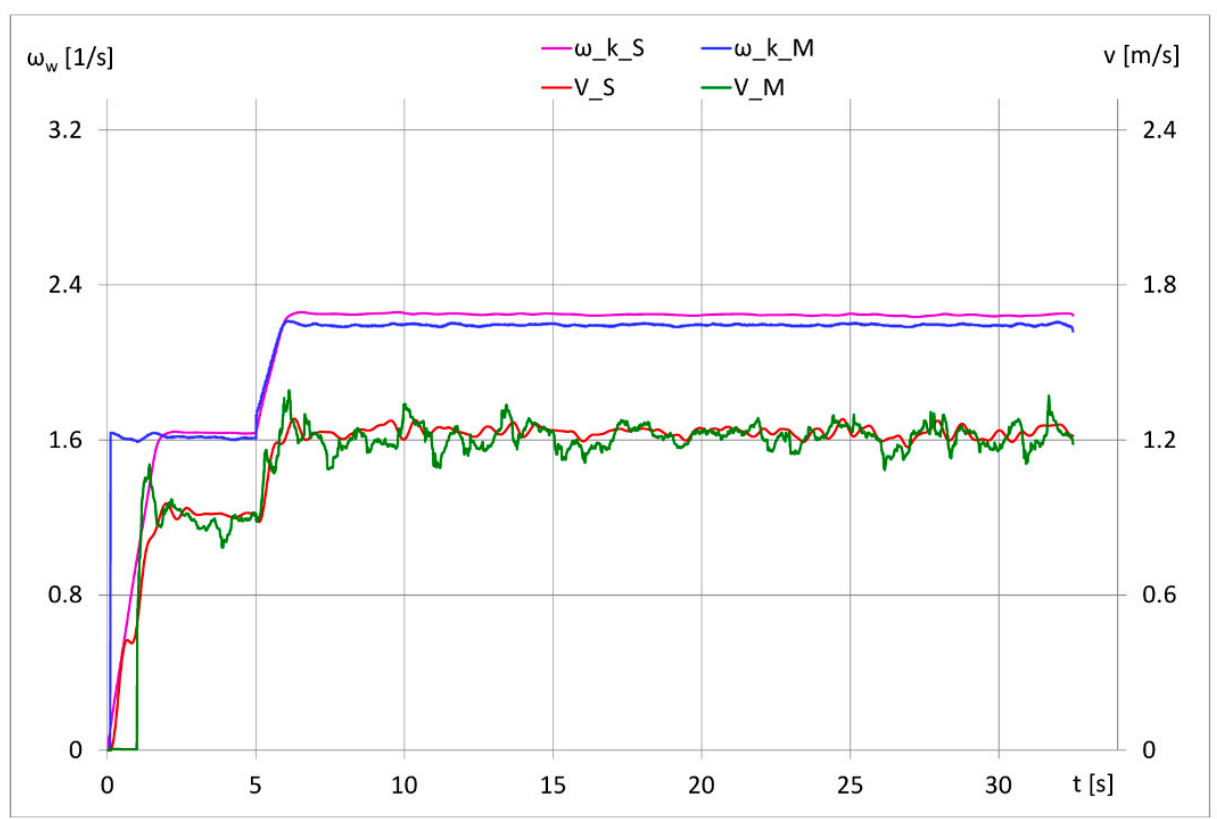

Figure 8. Changes in time of angular velocity of the drive wheel and tractor velocity, respectively; simulated $\left(\omega \_k \_S, v \_S\right)$, and measured in field tests $\left(\omega \_k \_M, v \_M\right)$, soil profile—silty loam, first gear.

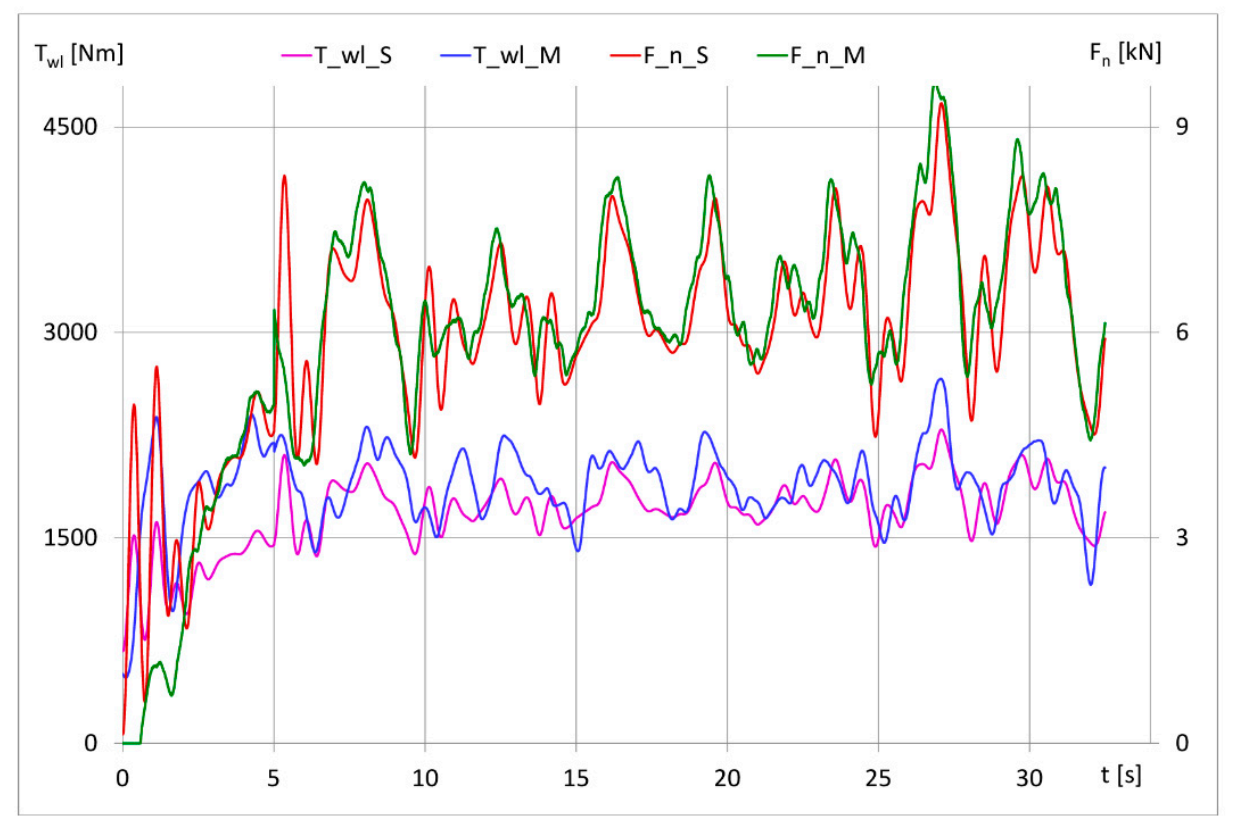

Figure 9. Changes in time of torques on drive wheels and tractor drive forces, respectively; simulated $\left(T \_w l \_S, F \_n \_S\right)$, measured in field tests $\left(T \_w l \_M, F \_n \_M\right)$, soil profile-silty loam, first gear.

A modified Nash-Sutcliffe coefficient (NS) was established for the values used in the validation of the model from Equation (12). The values of the modified Nash-Sutcliffe coefficient are presented in Table 1 for the full measurement range (second column) and proper operation of the unit (between 5 and $32 \mathrm{~s}$ - third column).

Values determined for the angular velocity of the drive wheel $\omega_{w}$ and linear velocity of the unit $v_{p}$ are above 0 , namely, 0.5 and 0.65 (full range), 0.5 and 0.55 (5-32 s range), respectively. This proves a very good efficiency of the model towards the experimental data. 
For the torque of drive wheel axle shaft $T_{w}$ and driving force of the tractor $F_{n}$, the value of the efficiency measure reached the values below 0 for the full range, -0.15 and -1.31 , respectively. In the initial period of simulation, significant changes in simulated values were observed. In the proper period of unit operation, it was between 5 and $32 \mathrm{~s}$. Therefore, it was decided that the value of the Nash-Sutcliffe coefficient should be determined for the time interval between 5 and $32.5 \mathrm{~s}$ for the torque of drive wheel axle shaft $T_{w}$ and the driving force of the tractor $F_{n}$. The values determined for the modified Nash-Sutcliffe coefficient are presented in Table 1 . For the torque of drive wheels $T_{w}$, the value of the efficiency measure reaches the value of 0.05 , while for the driving force of the tractor $F_{n}$ the value of adjustment measure reaches -1.18 .

Table 1. Value of the modified Nash-Sutcliffe (NS) factor.

\begin{tabular}{ccc}
\hline \multirow{2}{*}{ Values Assumed for Validation } & \multicolumn{2}{c}{ Values of Modified NS Coefficient } \\
\cline { 2 - 3 } & Full Range Time & 5-32 s Range \\
\hline angular velocity of the drive wheel $\omega_{w}$ & 0.50 & 0.50 \\
linear velocity of the unit $v_{p}$ & 0.65 & 0.55 \\
torque of the drive wheel axle shaft $T_{w}$ & -0.15 & 0.05 \\
driving force of the tractor $F_{n}$ & -1.31 & -1.18 \\
\hline
\end{tabular}

On the basis of the curves for registered values and the analysis of the research results, it can be claimed that the nature and the values of individual simulated values reflect their actual changes and thus the efficiency of the model is satisfactory.

\subsection{Simulation Results and Their Analysis}

The primary aim of the machine unit operation in the field is to satisfy agrotechnical requirements, i.e., loosening the soil to the required cutting depth, which was considered as the basic criterion of the evaluation. The performance criteria are the means to satisfy the principal aim, where total and tractive efficiency are taken into account, together with area productivity per unit of time and fuel consumption per unit of the cultivated field area. An excessively shallow treatment does not satisfy agrotechnical conditions and can cause a decrease in the crop yield. In turn, an excessively deep treatment results in reducing the effectiveness of the tractor aggregate performance (an unnecessary increase in expenditures).

The simulation tests were carried out in accordance with the experimental research plan. In order to compare the performance of the machine unit working in various field conditions (three soil profiles) depending on the selection of input values, i.e., adjustable (the drive train $i_{c}$, implement linkage control systems, i.e., $K$-support, $C$-pressure, or $S$-force; implement depth $a_{n}$ ) and determining the effects of those factors on the implement unit efficiency, a simulation of its performance was carried out.

To illustrate the changes in the travel speed of the unit $v$ and the slip of the tractor's drive wheels $s$ obtained in the second and the third gear with the enabled force control system, the set cutting depth $a_{n S 2}=0.19 \mathrm{~m}$ and soil profile-loamy sand are presented in Figure 10. In the second and third gear, the mean values of the unit velocity and the slip of the tractor's drive wheels, and standard deviations are, respectively, $v_{b 2}=1.56 \mathrm{~m} \mathrm{~s}^{-1}$, $s_{v b 2}=0.071 \mathrm{~m} \mathrm{~s}^{-1}, v_{b 3}=1.96 \mathrm{~m} \mathrm{~s}^{-1}, s_{v b 3}=0.0118 \mathrm{~m} \mathrm{~s}^{-1} ;$ slips- $s_{b 2}=11.78 \%, s_{s b 2}=3.921 \%$, $s_{b 3}=23.22 \%, s_{s b 3}=4.451 \%$. Based on the analysis of the velocity and the slip in the conditions specified above, operation of the unit in the third gear results in an increase in velocity by $25.6 \%$ in relation to driving in the second gear, and the slip of drive wheels increased by $97.1 \%$. 


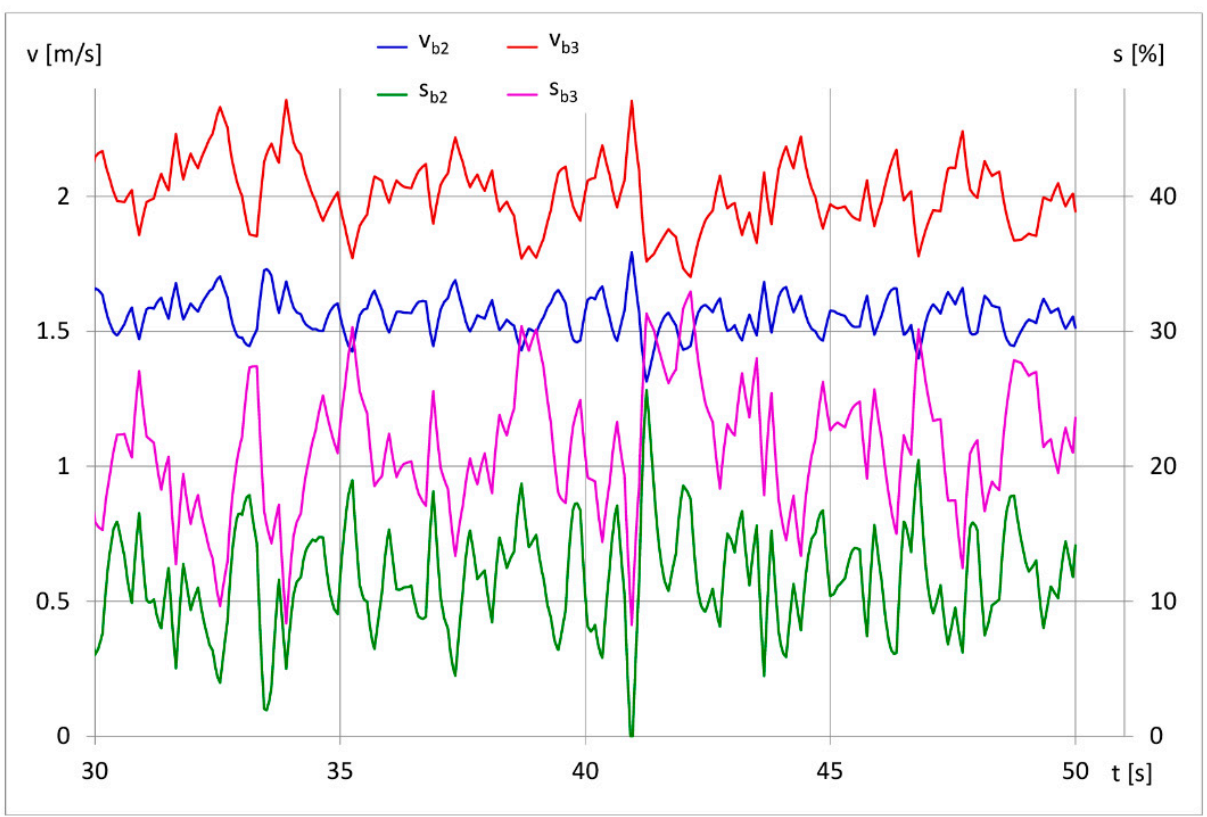

Figure 10. Changes in velocity of the unit $v_{b}$ and slip of drive wheels of the tractor $s_{b}$, respectively, in the second gear $\left(v_{b 2}, s_{b 2}\right)$ and in the third gear $\left(v_{b 3}, s_{b 3}\right)$; soil profile-loamy sand, and cutting depth setting $a_{n S 2}=0.19 \mathrm{~m}$.

Figure 11 presents changes in the values of tractive efficiency $\eta_{u}$ and total efficiency $\eta_{0}$ of the tractor unit with the force control system enabled, in the second gear, soil profile-silty loam, and operating depth $a_{n S 1}=0.13 \mathrm{~m}$.

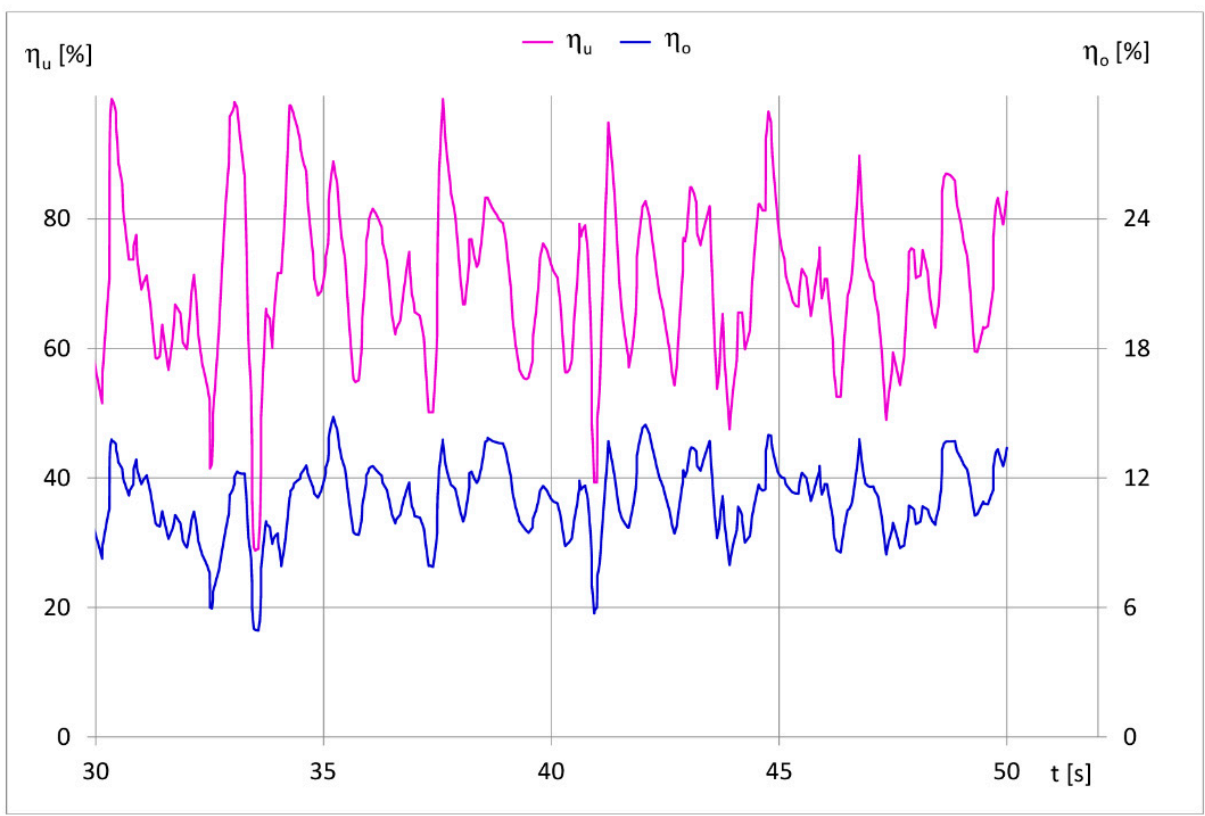

Figure 11. Changes in tractive efficiency $\eta_{u}$ and total efficiency $\eta_{o}$ of the tractor unit in the second gear, soil profile-silty loam, and depth setting $a_{n S 1}=0.13 \mathrm{~m}$.

Based on the research results (Figure 11), mean values of efficiency and their standard deviations were determined. They amounted to, respectively: $\eta_{u}=71.28 \%, s_{\eta u}=6.782 \%$, $\eta_{o}=11.02 \%, s_{\eta 0}=3.938 \%$.

Figure 12 presents the changes in the values of total efficiency $\eta_{0}$ and area productivity $W_{b}$ of the tractor unit with the force control system enabled, in the third gear, soil profile-medium clay, and depth setting $a_{n S 2}=0.19 \mathrm{~m}$. 


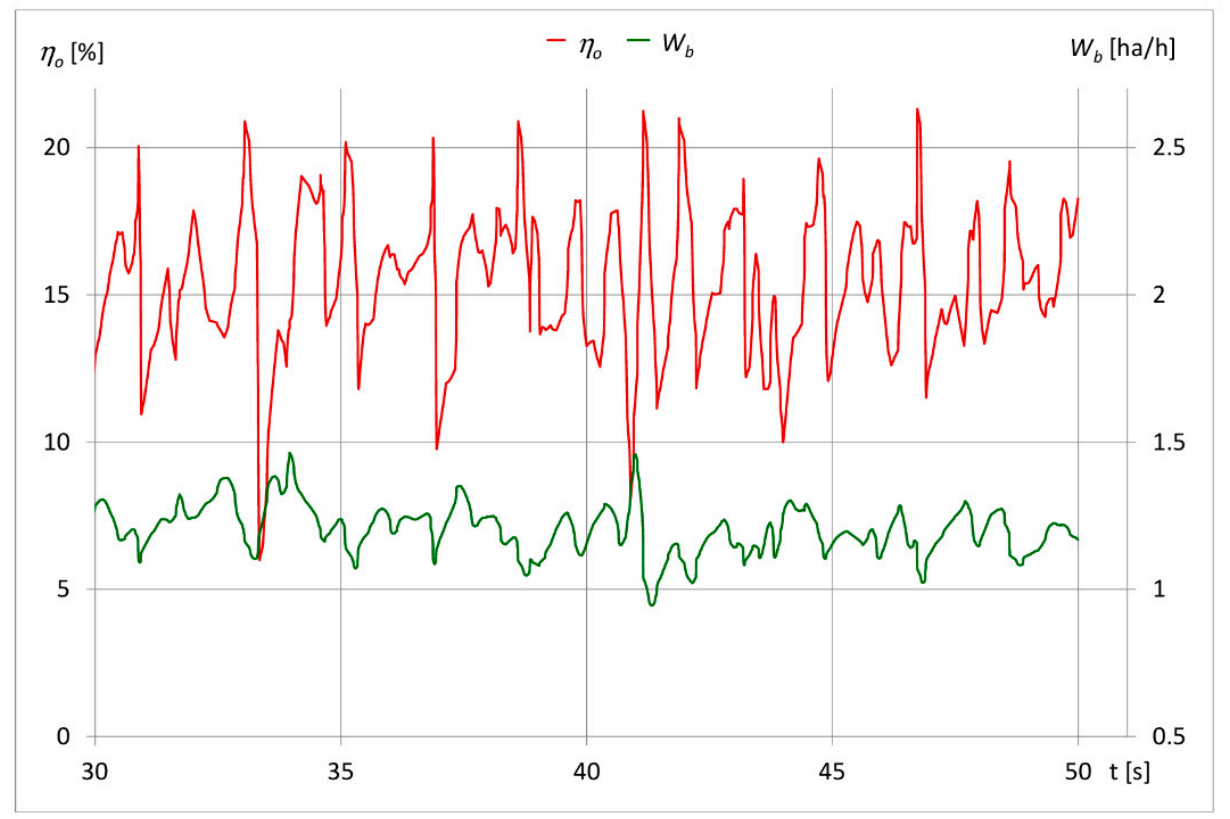

Figure 12. Changes in total efficiency $\eta_{o}$ and area productivity $W_{b}$ of the tractor unit in the third gear, soil profile-medium clay, and depth setting $a_{n S 2}=0.19 \mathrm{~m}$.

Based on the analysis of the simulation results (Figure 12), the following mean values of total efficiency $\eta_{o}$ and area productivity $W_{b}$ and their standard deviations were determined, respectively: $\eta_{o}=15.95 \%, s_{\eta o}=4.141 \%$, surface efficiency $W_{b}=1.17 \mathrm{ha} \mathrm{h}^{-1}$, and $s_{W b}=0.093 \mathrm{ha} \mathrm{h}^{-1}$.

Changes in total efficiency $\eta_{0}$ of the tractor unit and fuel consumption per hectare $G_{p}$, the first gear, soil profile-medium clay, depth setting $a_{n S 2}=0.19 \mathrm{~m}$, and force control system enabled are presented in Figure 13. On the basis of simulation results (Figure 13), the following mean values of total efficiency $\eta_{o}$ and fuel consumption $G_{p}$ per hectare were determined, and their standard deviations amount to, respectively: total efficiency $\eta_{o}=12.41 \%, s_{\eta o}=2.863 \%$, fuel consumption $G_{p}=5.07 \mathrm{dm}^{3} \mathrm{ha}^{-1}$, and $s_{G p}=0.587 \mathrm{dm}^{3} \mathrm{ha}^{-1}$.

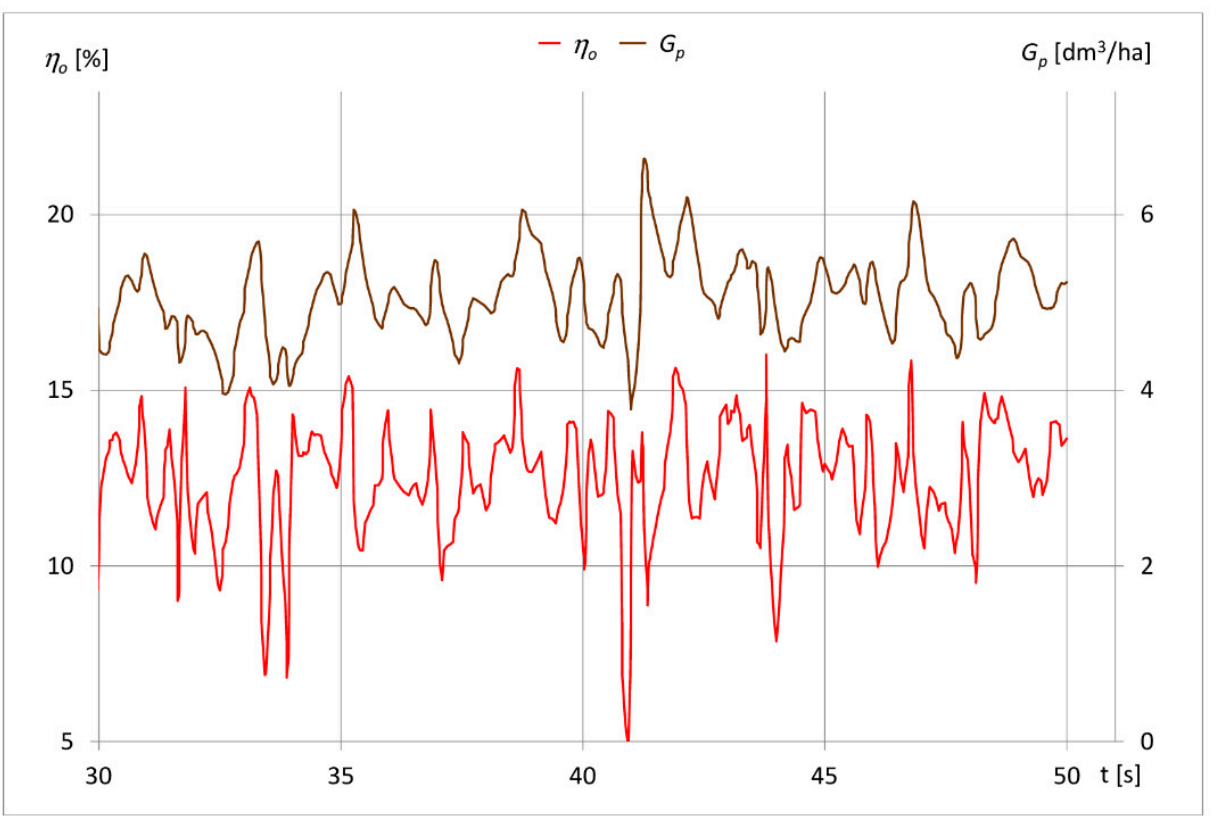

Figure 13. Changes in total efficiency $\eta_{o}$ of the tractor unit and fuel consumption per hectare $G_{p}$ in the first gear, soil profile-medium clay, and depth setting $a_{n S 2}=0.19 \mathrm{~m}$. 
Table 2 presents the mean values of the cutting depth and performance indicators of the tractor unit with enabled force system of the implement linkage adjustment, obtained as a result of simulation studies.

Table 2. Mean values of performance indicators of the unit with enabled force control of the implement linkage system for two cutting depth settings, three gears, and three soil profiles.

\begin{tabular}{|c|c|c|c|c|c|c|c|c|}
\hline \multirow{3}{*}{ Soil Profile } & \multirow{3}{*}{$\begin{array}{c}\text { Setting } a_{n} \\
\mathrm{~m}\end{array}$} & \multirow{3}{*}{ Gear } & \multicolumn{6}{|c|}{ Mean Indicator Values } \\
\hline & & & $a_{n S}$ & $s$ & $\eta_{u}$ & $\eta_{o}$ & $W_{b}$ & $G_{p}$ \\
\hline & & & $\mathbf{m}$ & $\%$ & $\%$ & $\%$ & ha $h^{-1}$ & $\mathrm{dm}^{3} \mathrm{ha}^{-1}$ \\
\hline \multirow{6}{*}{ Loamy sand } & \multirow{3}{*}{0.130} & $\mathrm{I}$ & 0.127 & 6.4 & 65.81 & 5.94 & 0.977 & 3.554 \\
\hline & & II & 0.126 & 8.5 & 69.22 & 9.15 & 1.274 & 3.160 \\
\hline & & III & 0.123 & 13.8 & 69.09 & 12.92 & 1.754 & 3.470 \\
\hline & \multirow{3}{*}{0.190} & $\mathrm{I}$ & 0.187 & 8.7 & 70.26 & 7.87 & 0.950 & 3.894 \\
\hline & & II & 0.186 & 11.7 & 73.20 & 11.42 & 1.224 & 3.676 \\
\hline & & III & 0.185 & 22.9 & 64.95 & 12.73 & 1.550 & 4.646 \\
\hline \multirow{6}{*}{ Silty loam } & \multirow{3}{*}{0.130} & $\mathrm{I}$ & 0.125 & 9.2 & 68.73 & 7.72 & 0.947 & 3.945 \\
\hline & & II & 0.127 & 13.1 & 71.28 & 11.02 & 1.205 & 3.784 \\
\hline & & III & 0.129 & 24.2 & 62.87 & 12.32 & 1.521 & 4.922 \\
\hline & \multirow{3}{*}{0.190} & $\mathrm{I}$ & 0.188 & 13.1 & 73.15 & 9.99 & 0.900 & 4.529 \\
\hline & & II & 0.188 & 19.8 & 69.88 & 12.36 & 1.107 & 4.774 \\
\hline & & III & 0.185 & 33.8 & 60.03 & 11.94 & 1.305 & 6.123 \\
\hline \multirow{6}{*}{ Medium clay } & \multirow{3}{*}{0.130} & I & 0.126 & 7.7 & 74.11 & 9.59 & 0.967 & 4.208 \\
\hline & & II & 0.128 & 10.3 & 74.75 & 12.93 & 1.241 & 4.332 \\
\hline & & III & 0.132 & 16.7 & 73.65 & 15.44 & 1.449 & 5.040 \\
\hline & \multirow{3}{*}{0.190} & I & 0.189 & 10.9 & 77.92 & 12.42 & 0.921 & 5.069 \\
\hline & & II & 0.192 & 17.0 & 74.33 & 14.30 & 1.132 & 5.844 \\
\hline & & III & 0.194 & 19.8 & 73.22 & 15.83 & 1.176 & 5.651 \\
\hline
\end{tabular}

On the basis of the simulation results presented in the table above, it can be seen that the most favorable values of individual performance indicators for the unit operating in a given soil profile are obtained at various working depths and transmissions in the drive train. For loamy sand at $a_{n}=0.13 \mathrm{~m}$, the highest values of tractive and total efficiency, as well as area productivity, were obtained in the third gear. The lowest value of fuel consumption was obtained in the second gear. The highest tractive efficiency and the lowest fuel consumption was obtained in the second gear at $a_{n}=0.19 \mathrm{~m}$ and the highest values of total efficiency and area productivity were recorded in the third gear. The bold values in the table are the maximum values of individual indicators.

\section{Conclusions}

After an analysis of tractive and total efficiency, as well as fuel consumption and area productivity (simulation results presented above, obtained in the same conditions, and in various gears), the following relations can be observed between the most favorable values of individual performance indicators of the machine unit: the highest value of the tractive efficiency is the lowest fuel consumption per hectare and the highest value of total efficiency is also the highest value of area productivity, with the reservation that the slip values range between $10.5 \%$ and $24.2 \%$.

The force control system for the soil of various resistance values (mosaic of soil types) requires the operator to adjust the depth setting in order to ensure uniform operating depth of the cultivator. In specific soil profiles characterized by varied physical and mechanical properties, it is necessary to manually adjust the resistance force as the leading value.

The model was developed to predict tractor fuel consumption based on operational requirements and traction conditions, and the application was demonstrated. Traction parameters of a two-wheel drive tractor and fuel consumption were assessed. The use of 
operational indicators of wheeled tractors can be used to optimize energy consumption. The effective operation of tractors in agricultural processes is crucial in terms of energy efficiency, economic consequences, and environmental footprint.

Funding: This research received no external funding.

Conflicts of Interest: The author declares no conflict of interest.

\section{Nomenclature}

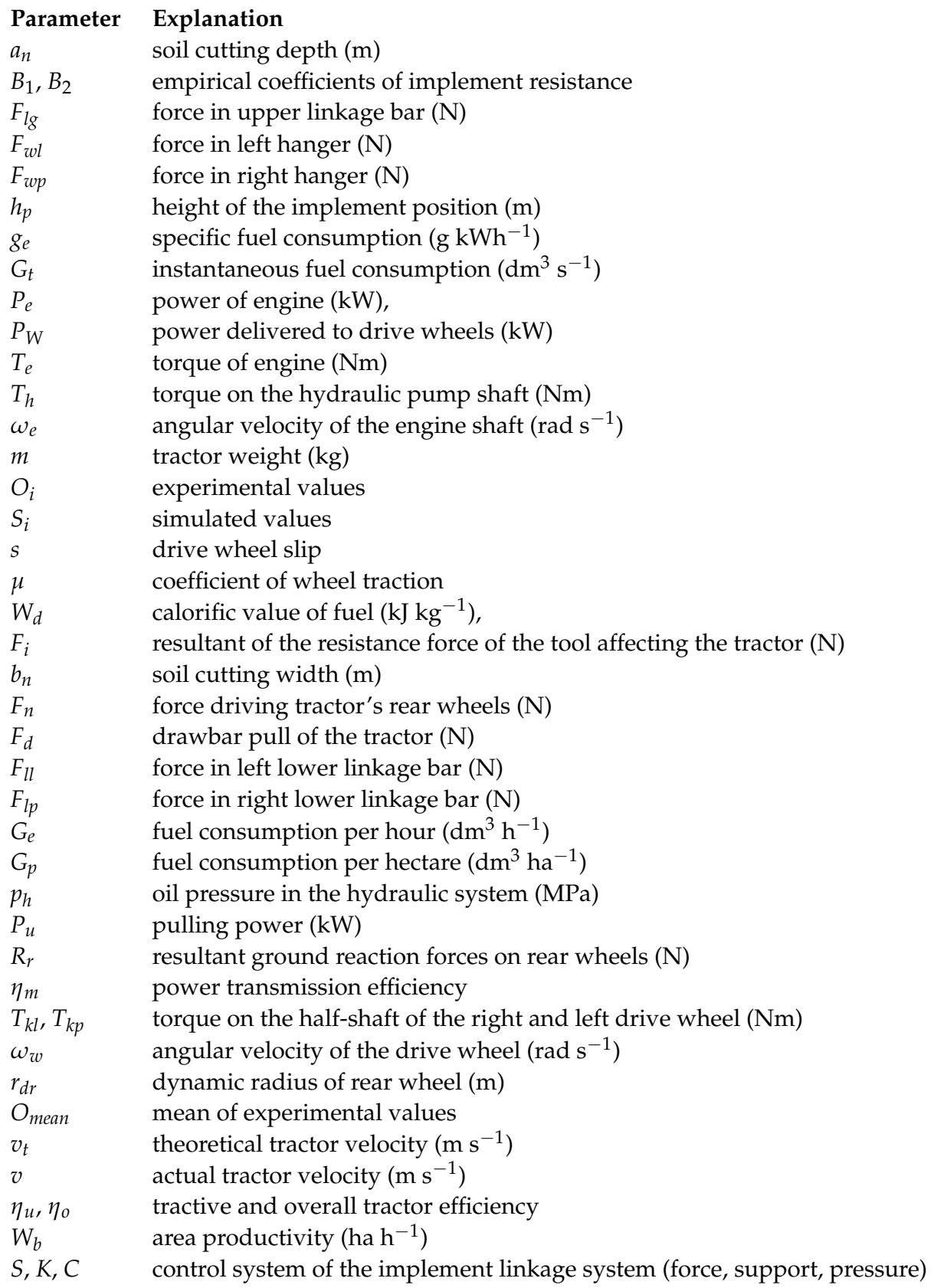

\section{References}

1. Zoz, F.M. Predicting Tractor Field Performance (Updated); Paper 87-1623; ASAE: St. Joseph, MI, USA, $1987 ;$ p. 12.

2. Sharma, A.K.; Pandey, K.P. Modelling power requirement for traction tyres with zero sinkage. J. Terramech. 1997, $34,13-21$. [CrossRef]

3. Shmulevich, I.; Osetinsky, A. Traction performance of a pushed/pulled drive wheel. Trans. ASAE 2004, 47, 981-994. [CrossRef] 
4. Elwaleed, A.K.; Yahya, A.; Zohadie, M.; Ahmad, D.; Kheiralla, A.F. Net traction ratio prediction for high-lug agricultural tyre. J. Terramech. 2006, 43, 119-139. [CrossRef]

5. Schreiber, M.; Kutzbach, H.D. Comparison of different zero-slip definitions and a proposal to standardize tire traction performance. J. Terramech. 2007, 44, 75-79. [CrossRef]

6. Simikić, M.; Dedović, N.; Savin, L.; Tomić, M.; Ponjičan, O. Power delivery efficiency of a wheeled tractor at oblique drawbar force. Soil Tillage Res. 2014, 141, 32-43. [CrossRef]

7. Battiato, A.; Diserens, E. Tractor traction performance simulation on differently textured soils and validation: A basic study to make traction and energy requirements accessible to the practice. Soil Tillage Res. 2017, 166, 18-32. [CrossRef]

8. Jenane, C.; Bashford, L.L.; Monroe, G. Reduction of fuel consumption through improved tractive performance. J. Agric. Eng. Res. 1996, 64, 131-137. [CrossRef]

9. Sahay, C.S.; Tewari, V.K. Computer simulation of tractor single-point drawbar performance. Biosyst. Eng. 2004, 88, 419-428. [CrossRef]

10. Portes, P.; Bauer, F.; Ćupera, J. Laboratory-experimental verification of calculation of force effects in tractor's three-point hitch acting on driving wheels. Soil Tillage Res. 2013, 128, 81-90. [CrossRef]

11. Kazemi, N.; Almassi, M.; Bahrami, H.; Shaykhdavoodi, M.J.; Mesgarbashi, M. Analysis of Factors Affecting the Management of Overall Energy Efficiency of Tractor-Implement by Real-Time Performance Monitoring. J. Agric. Mach. 2014, 4, $214-225$.

12. Lee, J.W.; Kim, J.S.; Kim, K.U. Computer simulations to maximise fuel efficiency and work performance of agricultural tractors in rotovating and ploughing operations. Biosyst. Eng. 2016, 142, 1-11. [CrossRef]

13. Keen, A.; Ward, J.; Godwin, R.; Cooper, S.; Hall, N. Improvements to the Tractive Efficiency of Agricultural Tractors Carrying out Cultivations; Paper Number: 096639; ASABE: St. Joseph, MI, USA, 2009.

14. Al-Janobi, A. A data-acquisition system to monitor performance of fully mounted implements. J. Agric. Eng. Res. 2000, 75, 167-175. [CrossRef]

15. Kim, Y.-S.; Kim, W.-S.; Siddique, M.A.A.; Baek, S.-Y.; Baek, S.-M.; Cheon, S.-H.; Lee, S.-D.; Lee, K.-H.; Hong, D.-H.; Park, S.-U.; et al. Power Transmission Efficiency Analysis of $42 \mathrm{~kW}$ Power Agricultural Tractor According to Tillage Depth during Moldboard Plowing. Agronomy 2020, 10, 1263. [CrossRef]

16. Ashok Kumar, A.; Tewari, V.K.; Nare, B. Embedded digital draft force and wheel slip indicator for tillage research. Comput. Electron. Agric. 2016, 127, 38-49. [CrossRef]

17. Čupera, J.; Bauer, F.; Severa, L.; Tatíček, M. Analysis of force effects measured in the tractor three-point linkage. Res. Agric. Eng. 2011, 57, 79-87. [CrossRef]

18. Md-Tahir, H.; Zhang, J.; Xia, J.; Zhou, Y.; Zhou, H.; Du, J.; Sultan, M.; Mamona, H. Experimental Investigation of Traction Power Transfer Indices of Farm-Tractors for Efficient Energy Utilization in Soil Tillage and Cultivation Operations. Agronomy 2021, 11, 168. [CrossRef]

19. Al-Hamed, S.A.; Al-Janobi, A.A. A program for predicting tractor performance in Visual C++. Comput. Electron. Agric. 2001, 31, 137-149. [CrossRef]

20. Grisso, R.D.; Kocher, M.F.; Vaughan, D.H. Predicting Tractor Fuel Consumption. Appl. Eng. Agric. 2004, 20, 553-561. [CrossRef]

21. Kolator, B.; Białobrzewski, I. A simulation model of 2WD tractor performance. Comput. Electron. Agric. 2011, 76, 231-239. [CrossRef]

22. Kim, W.S.; Kim, Y.J.; Chung, S.O.; Lee, D.H.; Choi, C.H.; Yoon, Y.H. Development of simulation model for fuel efficiency of agricultural tractor. Korean J. Agric. Sci. 2016, 43, 116-126. [CrossRef]

23. Li, B.; Sun, D.; Hu, M.; Liu, J. Research on Economic Comprehensive Control Strategies of Tractor-Planter Combinations in Planting, Including Gear-Shift and Cruise Control. Energies 2018, 11, 686. [CrossRef]

24. Li, T.; Xie, B.; Li, Z.; Li, J. Design and Optimization of a Dual-Input Coupling Powertrain System: A Case Study for Electric Tractors. Appl. Sci. 2020, 10, 1608. [CrossRef]

25. McBratney, A.; Whelan, B.; Ancev, T.; Bouma, J. Future directions of precision agriculture. Precis. Agric. 2005, 6, 7-23. [CrossRef]

26. Heywood, J.B. Internal Combustion Engine Fundamentals; McGraw-Hill Book Company: New York, NY, USA, 1988.

27. Olszewski, A. Wpływ Sterowania Trzypunktowym Układem Zawieszenia Narzędzia na Efektywność Funkcjonowania Agregatu Ciagnikowego. Ph.D. Thesis, Uniwersytet Warmińsko-Mazurski, Olsztyn, Poland, 2015.

28. Muleta, M.K. Model performance sensitivity to objective function during automated calibrations. J. Hydrol. Eng. 2011, 17, 756-767. [CrossRef]

29. Barbosa, R.N.; Wilkerson, J.B.; Denton, H.P.; Yoder, D.C. Slope Gradient and Vehicle Attitude Definition Based on Pitch and Roll Angle Measurements: A Simplified Approach. Open Agric. J. 2012, 6, 36-40. [CrossRef] 